
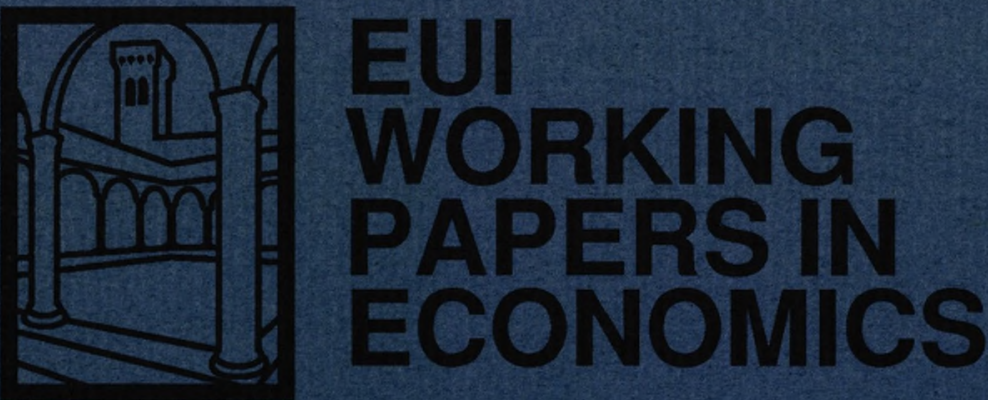

EUI Working Paper ECO No. $92 / 78$

Three Tests for the Existence of Cycles in Time Series

Fabio Canova 


\section{European University Library}

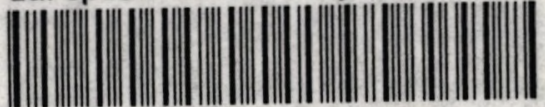

$300010013 \quad 48228$

\section{Please note}

As from January 1990 the EUI Working Paper Series is divided into six sub-series, each sub-series is numbered individually (e.g. EUI Working Paper LA W No. 90/1). 


\section{EUROPEAN UNIVERSITY INSTITUTE, FLORENCE}

ECONOMICS DEPARTMENT

EUI Working Paper ECO No. 92/78

Three Tests for the Existence of Cycles in Time Series

FABIO CANOVA 
All rights reserved.

No part of this paper may be reproduced in any form without permission of the author.

(c) Fabio Canova

Printed in Italy in May 1992

European University Institute

Badia Fiesolana

I-50016 San Domenico (FI)

Italy 


\title{
Three Tests for the Existence of Cycles in Time Series
}

\author{
Fabio Canova * \\ Department of Economics, Brown University \\ Providence, RI 02912, USA
}

and

Department of Economics, European University Institute

I-50010 San Domenico di Fiesole (FI), Italy

CANOVA@IFIIUE.bitnet

Telephone: 39-55-5092-252

Fax: 39-55-5092-202

This Revision: February, 1992

\begin{abstract}
Three tests for the presence of cycles in univariate time series are proposed. The asymptotic distribution of the tests is derived using the properties of the integrated spectrum. The small sample power of the tests is computed using simulated data. The tests are applied to US data to detect the existence of significant seasonal and of other types of periodic fluctuations.

JEL Classification No.: 131, 211

Key Words: Spectrum, Distance Test, Band Pass Test, Seasonality, Business Cycles.
\end{abstract}

"I would like to thank Steve Durlauf, Frank Diebold, Eric Ghysels, Bruce Hansen, Bruce Mizrach, Augustin Maravall for helpful comments. A special thank to Adrian Pagan for very useful suggestions. 


\section{Introduction}

This paper describes three tests to assess the significance of cycles in time series data.

There are several reasons to be interested in such tests. Time series analysts often identify cycles with peaks in the spectral density of a time series (e.g seasonal cycles in Sims (1974)). However, the question of the significance of these peaks has seldom been addressed. Business cycle practitioners are concerned with cyclical fluctuations in GNP and other variables, where cyclical fluctuations are measured as deviations from the trend of the process. Recent literature on unit roots in macroeconomics has suggested that these type of cycles may not even exist (see e.g. Nelson and Plosser (1982)). In general, there is no insurance that deviations from the trend are not just contaminated noise and that no interesting cyclical fluctuations really exist. Similarly, recent literature on Bayesian learning (see Nyarko (1990)) and on noisy traders in financial markets (see Kirman (1990)) has pointed out the possible existence of irregularly spaced but significant cycles in economic activity and prices. Further, in the political economy literature it has been argued that there are electoral cycles in government variables. These arguments imply, for example, a periodicity of four years in the growth rate of government expenditure (see Alesina and Roubini (1990)). Finally, a branch of the financial economic literature has examined the predictability of asset returns from particular speculative strategies in the short and in the long run (see e.g. Fama (1984), Poterba and Summers (1988) and Lo and MacKinley (1988)). The maintained hypothesis here is that efficiency implies martingale difference behavior for these variables. Therefore this literature is also interested in uncovering the presence of meaningful cycles in the data. A statistical test which allows us to formally assess whether significant cycles exist may therefore be useful to validate all these theories.

This paper presents a unified framework to test for the existence of periodic 
cycles of any specified but finite length or for the presence of irregularly spaced fluctuations in economic time series. The principle employed is general and the procedure encompasses tests for the existence of seasonal and cyclical fluctuations and of cycles of long but finite length as particular cases. The tests are concerned with univariate time series, are designed in the frequency domain, where the notion of cycles is well defined, do not require a-priori knowledge about which autocorrelations are important (as would be the case with time domain tests) and use the properties of the spectrum to derive the asymptotic distribution of the statistics of interest.

The paper is organized as follows: section 2 presents the definition of cycles employed and discusses the relationship with the concept of hidden periodicity recently employed by Hansen and Sargent (1990) and with the concept of cyclical fluctuations currently employed in the macro literature (see e.g. Kydland and Prescott (1990)). Section 3 describes the three test statistics, their asymptotic properties and the relationships among them. In section 4 a Monte Carlo study is performed to compute the small sample properties of the tests. In section 5 I apply the methodology to a number of post WWII U.S. macro series to detect the existence of seasonal, business and other interesting periodic fluctuations. Section 6 provides some conclusions.

\section{A definition of cycles}

Let $X_{t}$ be a general linear stochastic process with MA representation $X_{t}=g(\ell) e_{t}+\mu$ where $g(\ell)=g_{0}+g_{1} \ell+g_{2} \ell^{2} \ldots$ is one sided in nonnegative powers of the lag operator $\ell$ and satisfies $\sum_{j}\left|g_{j}\right||j|^{\zeta}<\infty, \zeta>0, \mu$ is the linearly deterministic component (possibly a vector of initial conditions) and $e_{t}$ is an independently distributed white noise. It is typical to say that $X_{t}$ exhibits cycles of period $r<\infty$ if the (nonnormalized) spectral density of $X_{t}$, denoted by $h_{x}(\lambda)$, has a peak or a large mass at $\lambda_{k}=\frac{2 k \pi}{r}, k=1, \ldots,\left[\frac{r}{2}\right]$, and where $\left[\frac{r}{2}\right]$ is the maximum integer less than or equal to $\frac{r}{2}$. This definition has been suggested by, e.g., Granger and Newbold (1986), 
Sargent (1986) and has been used by, e.g., Sims (1974) and Granger (1979) to identify seasonality in univariate time series.

One way to formalize the above notion of cycles is the following. Let the deterministic component of $X_{t}$ be modelled as an atom in the spectral measure. Then a cycle of length $r<\infty$ exists if:

$$
0<\int_{-\pi}^{\pi}\left|1-e^{-i \lambda r}\right|^{2} h_{x}(\lambda) d \lambda<\int_{-\pi}^{\pi} h_{x}(\lambda) d \lambda
$$

Since $\left|1-e^{-i \lambda r}\right|^{2}=2-2 \cos (\lambda r)$, equation (1) reduces to

$$
0<\int_{-\pi}^{\pi} h_{x}(\lambda) d \lambda<2 \int_{-\pi}^{\pi} \cos (\lambda r) h_{x}(\lambda) d \lambda
$$

To intuitively understand why (2) captures the essence of the definition of cycles provided by Granger and Newbold and Sargent note that since $\cos (\lambda r)$ changes sign over $[-\pi, \pi]$, the expression on the right hand side of (2) will be small (or even negative) unless the power of $h_{x}(\lambda)$ is concentrated in the region where $\cos (\lambda r)$ is large and positive. Therefore $X_{t}$ has cycles of length $r$ if $h_{x}(\lambda)$ has a sharp peak (or wide mass) in the neighborhood of some or all $\lambda_{k}$. Note that, because $\cos (\lambda r)$ is periodic $\bmod \left(\frac{2 \pi}{r}\right),(2)$ does not distinguish between cycles at $\frac{2 \pi}{r}$ or at one of its harmonics. In other words, $(2)$ is consistent with $X_{t}$ having only one peak as well as having several peaks at some or all $\lambda_{k}, k=1, \ldots,\left[\frac{r}{2}\right]$.

In the time domain (1) implies that

$$
\operatorname{var}\left[\left(1-\ell^{r}\right) X_{t}\right]<\operatorname{var}\left[X_{t}\right]
$$

or that $\beta_{r}=\frac{\operatorname{cov}\left(X_{t}, X_{t-r}\right)}{\operatorname{var}\left(X_{t-r}\right)}>\frac{1}{2}$. Hence cycles of length $r$ exist if the regression coefficient of $X_{t}$ on $X_{t-r}$ exceeds 0.5 , a result which corresponds to the notion that $X_{t}$ displays cycles of period $r$ if its correlogram shows high positive values at lag $r$ (see e.g. Granger and Newbold (1986, p.68)).

An example may further clarify the usefulness of (1) (or (3)) as a way to formalize the idea that there is a peak in the spectral density at frequency $\lambda_{k}$. Let $X_{t}=$ 
$-0.8 X_{t-1}+\epsilon_{t}$ with $\epsilon_{t} \sim(0,1)$. It is easy to check that $\beta_{1}=-0.8, \beta_{2}=0.64$, $\beta_{3}=-0.48, \beta_{4}=0.36$, etc.. Using the rule that a cycle of length $r$ exists if $\beta_{r}>0.5$, we find that $X_{t}$ displays cycles of order 2 as the intuition would suggest.

Next, I discuss some of the assumptions used. The condition imposed on the coefficients of the MA representation of $X_{t}$ is stronger than required and insures that the decay of the correlogram of $X_{t}$ is sufficiently rapid (see Walker, 1965). It implies absolute and square integrability of the $g_{j}$ 's and, therefore, second moment stationarity of $X_{t}$. It is more general than stationarity itself since it allows for the existence of cycles in non-stationary series which possess a smooth evolutionary spectrum (see Priestley, 1981, p.828).

Given that many economic time series display unit root like behavior, stationary inducing transformations are usually employed before the MA representation is derived, the autocorrelation function computed or the spectrum plotted. It is not the purpose of this paper to discuss the effects of incorrect transformations on the presence of cycles as there is a large literature dealing with "spurious cycles" in time series (see e.g. Nelson and Kang (1981), Quah and Wooldridge (1988) and Cogley and Nason (1991)). Instead, I will consider a situation where, given some transformation, the researcher spots a peak in the spectral density at some $\lambda_{k}$ and he is interested in examining its significance. From this perspective (1) (or (3)) and the tests I describe in this paper are valid independently of the stationary inducing transformation used. If, e.g. the spectrum of $Y_{t}=(1-\ell) X_{t}$ is plotted, because $X_{t}$ is found to be an $\mathrm{I}(1)$ process, then (1) must be transformed to:

$$
0<\int_{-\pi}^{\pi}\left|1-\sum_{j=1}^{r-1}(-1)^{j+1} e^{-i \lambda j}\right|^{2} h_{y}(\lambda) d \lambda<\int_{-\pi}^{\pi} h_{y}(\lambda) d \lambda
$$

and (3) to $\operatorname{var}\left[\left(1+\ell-\ell^{2} \ldots .+\ell^{r-1}\right) Y_{t}\right]<\operatorname{var}\left[Y_{t}\right]$. In the empirical section of the paper I briefly discuss how particular conclusions about the presence of cycles may be incorrectly drawn because of an inappropriate choice of the stationary inducing transformation. 
One important restriction, which is implicit in the formulation of the problem, is that (1) (or (3)) should be applied only to processes with $r<\infty$ (or $\lambda_{r}>0$ ). The notion of cycles employed in fact rules out the possibility of considering an $\mathrm{AR}(1)$ process with coefficient close to 1 as a legitimate candidate for the data generating mechanism of cycles, since an $\mathrm{AR}(1)$ produces a peak in the spectral density at frequency zero and therefore violates the restriction that $r<\infty$. Put in another way, this paper is interested in examining the significance of peaks in the spectral density at $0<\lambda_{r} \leq \pi$ which may be generated by, say, second order difference equations with complex roots. Although this prevents us from addressing questions concerning persistence, as in Cochrane (1988), or permanent components, as in Quah (1992), the restriction is not crucial if one is interested in examining the presence of meaningful periodic fluctuations of finite length.

Gladysev (1961), Tiao and Grupe (1980) and Hansen and Sargent (1990) have used the term "hidden periodicity" to characterize Markov processes whose transition law is not time invariant but is strictly periodic with period $r$. Although there are similarities between their definition and the formalization of the notion of cycles employed in this paper, at least two differences should be noted. First, a process which has cycles according to (2) need not have a time invariant representation as an $r \times 1$ vector stochastic process. Second, unless deterministic periodic components are modelled as point masses in the spectral density, the definition of cycles employed in this paper can not capture processes which are periodic in the mean (e.g. processes which are characterized by seasonal initial conditions). Note, however, that both definitions are meaningful only when $r<\infty$.

Finally, it is important to note that the notion of cycles used in this paper does not coincide with the current terminology employed in macroeconomics, where deviations from the trend of the process are interpreted as cyclical fluctuations (see e.g. Kydland and Prescott (1990)). According to the framework of this section, 
the concept of cyclicality used in macroeconomics means that $\int_{-\pi}^{\pi} F(\lambda) h_{x}(\lambda) d \lambda$ is large where $F(\lambda)$ is a high pass filter, i.e. a filter with $F(\lambda)=0$ for $0<|\lambda|<\bar{\lambda}$ and $F(\lambda)=1$ for $\bar{\lambda}<|\lambda|<\pi$ and $\bar{\lambda}$ is some predetermined frequency, that $H(\lambda)=$ $F(\lambda) h_{x}(\lambda)$ is significantly different from a white noise and that, for any chosen series (say $W_{t}$ ), $\frac{1}{2 \pi} \int C o_{X, W}(\lambda) d \lambda$ is large where $\operatorname{Co}_{X, W}(\lambda)$ is the coherence of $W_{t}$ and $X_{t}$ at frequency $\lambda$. Note if $X_{t}$ and $W_{t}$ are two $\operatorname{AR}(1)$ processes with roots close to 1 , they may satisfy these conditions while they would not satisfy (1). In general, (1) is more restrictive than the condition that the filtered series displays meaningful fluctuations and comovements with a reference series and leads to a more appealing concept of periodic cycles.

\section{The Tests}

To set up the tests I will use a slightly modified version of (2) with $I_{n, x}(\lambda)=\frac{I_{n, x}(\lambda)}{4 \pi}$ in place of $h_{x}(\lambda)$, where $I_{n, \hat{x}}(\lambda)=\frac{2}{n}\left|\sum_{t} X_{t} e^{i \lambda t}\right|^{2}$ is the periodogram of $X_{t}$ based on $n$ observations at frequency $\lambda$. In this case equation (2) becomes

$$
2 \int_{-\pi}^{\pi} \cos (\lambda r) I_{n, x}(\lambda) d \lambda>\int_{-\pi}^{\pi} I_{n, x}(\lambda) d \lambda>0
$$

The rationale for using $I_{n, x}(\lambda)$ in place of $h_{x}(\lambda)$ is that an estimate of the former is easily obtained from the data. Priestley (1981, theorem 6.2.4, p.427) shows that, if $e_{t}$ are independently and normally distributed, this substitution is innocuous since the quantities in (2) are unbiasedly estimated (asymptotically) by the quantities in (5). If $h_{x}(\lambda)$ has bounded first derivatives, the order of magnitude of the bias is $O\left(\frac{\log (n)}{n}\right)$ which vanishes as $n \rightarrow \infty$. In addition, since both 1 and $\cos (\lambda r)$ are fixed bounded functions independent of $n$, and since $n \operatorname{var}\left[I_{n, x}(\lambda)\right] \stackrel{n \rightarrow \infty}{\longrightarrow} h_{x}^{2}(\lambda)$, the quantities in (5) consistently estimate the quantities in (4) (see, e.g. Priestley, 1981, p. 473$)$.

For the rest of the paper I make the following two assumptions: 
Assumption 1: $e_{t}$ is an independent Gaussian process with variance $\sigma_{e}^{2}$. Assumption 2: $\sum_{j}\left|g_{j}\right||j|^{\zeta}<\infty$.

\subsection{A distance-type test}

The idea of the test is simple. We want to know whether the difference between the two quantities in (5) is significant relative to their variances. Taking discrete approximations to the integrals in (5) at $\lambda_{k}=\frac{2 k \pi}{n}, k=0, \ldots,\left[\frac{n}{2}\right], n \geq N$, for some $N$ and using the symmetry of $I_{n, x}(\lambda)$ around $\lambda=0,(5)$ becomes

$$
2 \sum_{k} \cos \left(\lambda_{k} r\right) I_{n, x}\left(\lambda_{k}\right)>\sum_{k} I_{n, x}\left(\lambda_{k}\right)>0
$$

The next lemma characterizes the asymptotic properties of the quantities in (6):

Lemma 1: Let $A_{1 n}=\frac{4 \pi}{n} \sum_{k} I_{n, x}\left(\lambda_{k}\right)=\frac{M}{n} \sum_{k} W_{1}\left(\lambda-\lambda_{k}\right) I_{n, x}\left(\lambda_{k}\right)$ and $A_{2 n}=$ $\frac{4 \pi}{n} \sum_{k} \cos \left(\lambda_{k} r\right) I_{n, x}\left(\lambda_{k}\right)=\frac{M}{n} \sum_{k} W_{2}\left(\lambda-\lambda_{k}\right) I_{n, x}\left(\lambda_{k}\right)$ where $W_{1}\left(\lambda-\lambda_{k}\right) \equiv \frac{4 \pi}{M}, W_{2}(\lambda-$ $\left.\lambda_{k}\right) \equiv \frac{4 \pi \cos \left(\lambda_{k} r\right)}{M}$ and where $\mathrm{M}$ is a parameter regulating the length of $W_{1}$ and $W_{2}$ and depends on $n$. Then

$$
\begin{array}{ll}
\lim _{n \rightarrow \infty} \sqrt{\nu_{1}} A_{1 n} & \stackrel{D}{\longrightarrow} \mathcal{N}\left(H_{1}, H_{1}^{2}\right) \\
\lim _{n \rightarrow \infty} \sqrt{\nu_{2}} A_{2 n} \stackrel{D}{\longrightarrow} \mathcal{N}\left(H_{2}, H_{2}^{2}\right)
\end{array}
$$

where $\nu_{1}=\frac{n}{\pi \sum_{k} h\left(\lambda_{k}\right)^{2}}, \nu_{2}=\frac{n}{\pi \sum_{k} \cos \left(\lambda_{k} r\right)^{2} h\left(\lambda_{k}\right)^{2}}, H_{1}=\frac{4 \pi}{n} \sum_{k} h_{n, x}\left(\lambda_{k}\right), H_{2}=\frac{4 \pi}{n} \sum_{k} \cos \left(\lambda_{k} r\right) h_{n, x}\left(\lambda_{k}\right)$ 光

Lemma 1 follows from the normality of $e_{t}$, the asymptotic independence of the normalized periodogram estimates and the fact that $\chi^{2}$ variates with a large number of degrees of freedom behave like normal random variables. The only complication 
emerges because linear combinations of $\chi^{2}$ variates with unequal weights are not necessarily $\chi^{2}$. Using the trick discussed in Fuller (1981, p. 295-296) it is possible to overcome this problem.

From lemma 1 it is clear that $A_{1 n}$ and $2 A_{2 n}$ are different but not independent kernel estimators of the same quantity with kernels given by $W_{1}\left(\lambda_{k}-\lambda\right)$ and $W_{2}\left(\lambda_{k}-\right.$ ג). The distance test I propose is based on the idea that the difference between these two ways of estimating the same quantity is small under the null hypothesis (and large under the alternative) in the metric given by the variances of $A_{1 n}$ and $2 A_{2 n}$. Let $J_{1 n}=\frac{1}{\sqrt{\nu_{1}}} \frac{A_{1 n}-E A_{1 n}}{\sqrt{\operatorname{var}\left(A_{1 n}\right)}}$ and $J_{2 n}=\frac{1}{\sqrt{\nu_{2}}} \frac{A_{2 n}-E A_{2 n}}{\sqrt{\operatorname{var}\left(A_{2 n}\right)}}$ and consider the quadratic form:

$$
B_{n}=\left(2 J_{2 n}-J_{1 n}\right)\left(\operatorname{var}\left(2 J_{2 n}-J_{1 n}\right)\right)^{-1}\left(2 J_{2 n}-J_{1 n}\right)
$$

Corollary 1: $\lim _{n \rightarrow \infty} B_{n}=B \sim \chi^{2}(1)$.

Corollary 1 follows from the evaluation of the quantities of interest in the limit. Under the null hypothesis that no cycles of length $r$ exist in the data, $B_{n}$ will not significantly exceed a predetermined value $Z_{\alpha}$ at $\alpha \%$ confidence level.

To implement the test it is necessary to specify a-priori the length $r$ of the cycles we want to detect which is not always feasible. For example, one may observe a peak in the periodogram but may be unable to exactly identify whether the peak is due to cycles of length $r$, to cycles of length $r \pm \epsilon$ or to the spillover effect of neighbouring frequencies. In this case the test may be cumbersome to implement since one should test for each $r$ covering the frequencies in the interval. Alternatively, one may be concerned with the behavior of a series in a band of frequencies $\left[\lambda_{1}, \lambda_{2}\right]$ and therefore with cycles of length belonging to the interval $\left[\frac{2 \pi}{\lambda_{2}}, \frac{2 \pi}{\lambda_{1}}\right]$. Finally, if the periodicity is not exact, as is the case with time varying cycles, testing for a single $r$ may not be so useful.

One case where the test is appropriate is when one attempts to detect stable seasonal patterns. Seasonality appears at some $\lambda_{k}=\frac{2 \pi k}{s}, k=1, \ldots,\left[\frac{s}{2}\right]$, where $s$ is 
the number of seasons in the year. Correspondingly $X_{t}$ exhibits seasonal behavior if $\operatorname{var}\left[\left(1-\ell^{s}\right) X_{t}\right]<\operatorname{var}\left[X_{t}\right]$ (see Canova (1989) for an application).

\subsection{A test based on band spectrum variances}

The next test is based on the behavior of the spectrum in the band around some $\lambda_{k}$. Here I assume that a time series analyst observes a peak (or a large mass) in the periodogram of $X_{t}$ in a band around some $\lambda_{k}$ and is interested in assessing its significance, i.e., in testing if cycles of mean length $\frac{r}{k}$ are important, where $r$ corresponds, e.g. to business cycle periodicity. For this purpose consider the quantities:

$$
\begin{aligned}
C_{1 n} & =\frac{\sum_{\lambda_{k} \in \Gamma} I_{n, x}\left(\lambda_{k}\right)}{2\|\Gamma\|} \\
C_{2 n} & =\frac{\sum_{\lambda_{k} \in \Omega-\Gamma} I_{n, x}\left(\lambda_{k}\right)}{2\|\Omega-\Gamma\|}
\end{aligned}
$$

where $\Omega=[-\pi, \pi]$, and $\|$.$\| represents the number of periodogram ordinates in the$ interval. $C_{1 n}$ and $C_{2 n}$ measure the average power of $X_{t}$ inside the band $\Gamma$ centered around the frequency $\lambda_{k}$, for some $k$, and outside the band $\Gamma$, respectively. If the periodic component in the band $\Gamma$ is the only one existing in $X_{t}$, then the null hypothesis of the test is $C_{1 n}=C_{2 n}$, i.e. we test if the average amount of power inside the band $\Gamma$ is identical to the average amount outside the band. Notice that under this null hypothesis $X_{t}$ is a white noise. Under the alternative cycles of mean length $\frac{r}{k}$ exist.

Next, I derive the distribution of the statistic $D_{n}=\frac{C_{1 n}}{C_{2 n}}$ under the null hypothesis that $X_{t}$ is a white noise and under the alternative that cycles of mean length $\frac{r}{k}$ exist.

Lemma 2: Under $H_{0}$ and as $n \rightarrow \infty, G=2\|\Omega-\Gamma\| D_{n} \rightarrow \chi^{2}(2\|\Gamma\|)$. Under $H_{1}$ and as $n \rightarrow \infty, G \rightarrow \frac{\chi^{2}\left(\nu_{3}\right) E(G)}{\nu_{3}}$ where $\nu_{3}=\frac{32 n\|\Gamma\|}{\sum_{k} h_{n, x}^{2}\left(\lambda_{k}\right)}$. 
Lemma 2 employs the fact that under the null $C_{1 n}$ and $C_{2 n}$ are weighted averages of $\chi^{2}$ with equal weights while under the alternative the weights are frequency dependent. I normalize $D_{n}$ by $2\|\Omega-\Gamma\|$ because the nonnormalized quantity has a degenerate distribution as $n \rightarrow \infty$. Note that, in general, it is hard to predict the direction of the shift of the distribution under the alternative. However, for $n$ large enough, $2\|\Gamma\|<\nu_{3}$.

One may expect the power of the test to be affected by the presence of multiple peaks in the spectral density. For example, if a second peak occurs outside (inside) $\Gamma$, the null hypothesis may not (may) be rejected even though the first peak is (not) significant. Multiple peaks are not so crucial here because the averaging procedure employed consistently reduces the effect of a secondary peak in the spectrum. The only instance when this may become a problem is when the magnitude of the second peak is of an order larger than the peak we are testing for. In this case, the data need to be appropriately transformed before the test is computed.

\subsection{A test based on band-pass series}

Finally, I propose a third test based on the idea that if a peak in the periodogram of $X_{t}$ is significant, its contribution to the total variance of the process should be nonnegligible. Thus, if we filter the series so as to eliminate the peak, the leftover variance will be significantly different from the variance of the original series. Let $\tilde{X}_{t}=X_{t}-f\left(X_{t}\right)$ where $f\left(X_{t}\right)=\int_{\Omega^{\prime}} e^{i \lambda t} d Z_{x}(\lambda) ; \Omega^{\prime}=\left[\frac{2 \pi k}{r}-\epsilon, \frac{2 \pi k}{r}+\epsilon\right], Z_{x}(\lambda)$ is the spectral measure of $X_{t}$ and the integral is of the Fourier-Stieltjes variety. $\tilde{X}_{t}$ is the filtered series and $f($.$) a band-pass filter which wipes out the power of X_{t}$ on $\Omega^{\prime}$. Let $M$ be a parameter controlling the number of periodogram ordinates in a $2 \epsilon$ neighborhood of $\lambda_{k}=\frac{2 \pi k}{r}$ and let $W_{3}\left(\lambda_{k}\right) \equiv \frac{h_{\tilde{x}}\left(\lambda_{k}\right)}{h_{x}\left(\lambda_{k}\right)}$. Under $H_{0}, W_{3} \approx 1$. Define, $K_{n}=\sum_{k} \frac{I_{n, x}\left(\lambda_{k}\right)}{h_{x}\left(\lambda_{k}\right)}$ and $\tilde{K}_{n}=\sum_{k} \frac{I_{n, x}\left(\lambda_{k}\right)}{h_{x}^{*}\left(\lambda_{k}\right)}$. 
Lemma 3: Under $H_{0}, \lim _{n \rightarrow \infty} 2 \sqrt{\tilde{K}_{n}} \rightarrow \mathcal{N}\left(\sqrt{4\left(\left[\frac{n}{2}\right]-1\right)-1}, 1\right)$. Under $H_{1}, \lim _{n \rightarrow \infty} 2 \sqrt{\tilde{K}_{n}} \rightarrow$ $\mathcal{N}\left(\sqrt{2 \nu_{4}-1}, 1\right)$ where $\nu_{4}=\frac{2 n}{M \sum_{k} W_{3}^{2}\left(\lambda_{k}\right)^{2}}$.

The lemma follows from the fact that under $H_{0}, 2 \sqrt{\tilde{K}_{n}}$ has the same asymptotic $\chi^{2}$ distribution as $2 \sqrt{K_{n}}$, while under the alternative the centrality parameter of the distribution is shifted to the left. Therefore, if cycles of length $r$ exist in the data, a mass larger than what is expected under the null will appear in the tails of the distribution.

The test proposed in this section is similar in spirit to the one presented in section 3.1. As the first test, it compares the variance of the filtered and the original series. However, in section 3.1 the filter used was $2-2 \cos (\lambda r)$, which eliminates power at each $\lambda_{k}$ and introduces extraneous power at frequencies in between. Here the filter is a window which sets to zero the power at one $\lambda_{k}$ and leaves unchanged the power outside a $2 \epsilon$ band centered around this frequency.

\subsection{Comparisons across tests and the relationship with the existing literature}

Although all the three tests are designed to assess the significance of cycles of length $r$, they present several differences. As already noted, the filter used in the distancetype-test knocks out power in the neighborhood of each $\frac{2 \pi k}{r}$ and adds power in the neighborhood of each $\left(\frac{2(k-1) \pi}{r}\right)$. There are two implications of this fact. First, if the series truly has cycles of length $r_{1}$ and we specify $r=k r_{1}, k=1, \ldots,\left[\frac{n}{2}\right]$, the null hypothesis will be steadily rejected. Second, a misspecified value for $r$ may result in negative values of $A_{2 n}$. Since (5) requires $2 A_{2 n}-A_{1 n}$ to be positive and since $A_{1 n}$ is positive everywhere on $\lambda$, the sign of $A_{2 n}$ provides a pre-test procedure to detect an inappropriate specification for $r$. For example, if $X_{t}$ is a white noise, $A_{2 n}$ is non-positive for all $r$. 
Since the other two tests are concerned with only one particular band (as opposed to the entire spectrum of frequencies), they are free from the above implications. The second test can be used to clarify which of the harmonics of the basic frequency $\lambda_{k}$ is important in creating cycles of length $r$. Therefore, it provides a way to correct for the folding problem encountered in the first test. However, the test is subject to a certain amount of misspecification, since cycles of length $\mathrm{r}$ are identified up to a $2 \epsilon$ interval.

The third test may encounter problems when multiple peaks appear in the spectrum. In practice, this problem may not be substantial since existing economic time series rarely deviate from Granger's (1961) "typical spectral shape" unless seasonals are present. In addition, even though a peak may be sizable, its contribution to the total variance may be relatively small (e.g. when the peak is very sharp). In this case the test may be unable to assess the existence of a cycle unless the magnitude of the peak is substantial.

Finally, even though the alternative is the same in all three cases (i.e. cycles of length $\mathrm{r}$ exist in the data), the tests examine different null hypotheses. In the distance test the null hypothesis is that no significant periodic component exists in any band corresponding to cycles of length $r$. In the average variance test the null hypothesis is that $X_{t}$ is a white noise. In the band pass test the null hypothesis is that no significant periodic component exists at a particular harmonic frequency of cycles of length $r$. Therefore, one should expect the tests to differ in their acceptance rates and in their small sample properties.

The first and second tests proposed here share features with what Priestley calls the "Bartlett homogeneity test" (see 1981, p.487). That test was designed to check if independent estimates of the variance of the same quantity are significantly different. The statistic used, however, is slightly different from the ones employed in here. The second test has also some relationship with Fisher (1929) and Whittle (1952) tests for 
jumps in the integrated spectrum. The major difference is that while the statistics they use takes the max periodogram ordinate to the sum of periodogram ordinates over the entire range of frequencies, here I take the average periodogram ordinate over a band to an average of periodogram ordinates over the remaining range of frequencies. The reason for choosing averages is that there are situations where peaks may not be very sharp and yet there is a large mass concentrated around a particular frequency (e.g. the case of time varying seasonals or business cycle fluctuations). In this case the Fisher-Whittle test may fail to detect meaningful economic cycles which are irregularly concentrated around a particular frequency. On the other hand, if a significant mass appears in a band, the averaging procedure employed here allows the test to detect the presence of periodic components.

In independent work Durlauf (1991) designed a spectral based test for the martingale hypothesis which is similar to the second test presented here. His formulation builds on work by Grenander and Rosenblatt (1957) and is more general than mine since it allows for nonnormal and weakly dependent disturbances and for a generally specified alternative hypothesis. It is different since his test uses the properties of the integrated periodogram while here I use the properties of the spectrum. Durlauf's procedure has advantages and disadvantages. Because of its level of generality, his approach is free from data-mining activities which may affect the distribution of the test statistic under the null (see e.g. Hansen (1990)). However, there are many situations when a researcher has a priori knowledge about the possible location of interesting cycles in the data (e.g. seasonal or political cycles). In this case his tests may be less powerful than those described here in testing against a specific alternative. In addition, since Durlauf's tests are designed to assess general deviations from the white noise assumption, they can not be used to examine questions such as: Is the total power at seasonal frequencies significantly different from a white noise? The distance-type test presented here, on the other hand, can be used for 
this purpose. Finally, while Durlauf's procedure is valid also for $r=\infty$ the tests designed here are appropriate only when $r<\infty$.

\section{The small sample power of the tests}

This section describes the results of a Monte Carlo study designed to assess the small sample properties of the tests. I use five different data generating mechanisms (DGM):

$$
\begin{aligned}
\text { I) } & x_{t}=5.0+b x_{t-1}+e_{t} \\
\text { II) } & x_{t}=5.0+b x_{t-4}+e_{t} \\
\text { III) } & x_{t}=5.0+b x_{t-4}+c x_{t-7}+d x_{t-20}+e_{t} \\
I V) & x_{t}=5.0+e_{t}+f e_{t-1} \\
\text { V) } & x_{t}=e_{t}
\end{aligned}
$$

where $e_{t}$ is an i.i.d. $\mathcal{N}(0,1)$ random variable. Initial conditions $x_{-s}, s=0,1, \ldots, 20$ and $e_{0}$ are set equal to zero. In I) $b$ is equal to $(-0.9,-0.2)$. In II) $b$ is chosen to be equal to $( \pm 0.85, \pm 0.3)$. In III) the values for the triplet $(b, c, d)$ are either $[-0.68,0.16,-0.34]$ or $[0.80,-0.22,0.30]$. In IV) $\mathrm{f}=(0.8,0.2)$.

Experiment I) covers the case of cycles with a periodicity of 2 . With $b=-0.2$ the DGM generates samples where the regression coefficient of $x_{t}$ on $x_{t-r}$ is smaller than 0.5. Experiment II) covers the case of cycles of 4 and 8 periods with power at all of their harmonics. Experiment III) covers the case of high order dynamics with cycles of 14 and 20 periods respectively and power at most of their harmonics. Experiment IV) examines the power of the tests against a process with a short memory and not very significant serial correlation. Experiment V) similarly examines the power of the tests when the underlying process is a white noise. In this case I search for the highest peak in the periodogram and test for its significance. 
For each coefficient setting two sample sizes, $n=60$ and $n=154$, are considered. While the first sample size is arbitrary, the second sample size is typical of those series used in section 5. The number of ordinates taken in the discrete Fourier transform is 200 for each sample size. The window $\Gamma$ is chosen to contain 5 ordinates and the band over which the power of the spectral density is wiped out in the third test contains 5 ordinates as well. Bartlett windows are used to smooth periodograms. The number of replications in each case is equal to 1000 .

The results of the study appear in table 1 where I tabulate the percentage of rejections of the null hypothesis over replications. There are the two numbers in each cell, the first is the percentage for $n=60$, the second the percentage for $n=154$. Note that since the samples used are short, estimates of the low frequency components of the series are unreliable. Therefore, tests for cycles of long length should be interpreted with caution.

The results of the table are encouraging. Test 1 performs well and type I error is around its nominal size of $5 \%$ in almost all cases. The nonnegativity constraint on the quantities in (5) provides a useful sufficient condition to check for misspecifications of $r$. As expected, the test fails when the true $r$ generates cycles at harmonics of the frequency corresponding to the cycles we are testing for.

Test 2 is quite accurate. In general, its performance improves with the sample size and is best at frequencies away from 0 . When the sample size is small, the test fails to detect the presence of infinite cycles. Also, the test is weak in distinguishing cycles when the true band and the band we test for contain some common frequencies. For example, the test is unable to distinguish between significant cycles of 20 quarters and insignificant cycles of 24 quarters. In these situations when the null is false, the percentage of rejections is close to 0 .

The performance of the third test is reasonable but less powerful than the others. Its accuracy depends on the sharpness of the peaks in the spectral density. Bor- 
derline cases of processes with low correlation at lag $r$ or specifications where the sample size is small produce a percentage of type II errors sufficiently large. With low parameter values, increasing the sample size does not substantially improve the performance of the test. The reason is that when a process has low serial correlation the peaks are "unclean" and the power of the test is weakened when these peaks spillover into adjacent frequencies.

In conclusion, whenever the generating process has parameter values which induce sharp peaks in the spectral density of $X_{t}$ all three tests are accurate. For generating processes with borderline parameter values or for small sample sizes, the first two tests outperform the third, with the distance test being subject only to misspecification at the harmonics of the basic frequency.

\section{An application}

In this section I apply the three tests to detect the presence of seasonals, political cycles, certain types of business cycle fluctuations and deviations from the martingale behavior. Canova (1989) applies these tests to detect the presence of significant predictable components in profits from forward speculation in foreign exchange markets. In this exercise I use quarterly seasonally nonadjusted data on GNP, consumer purchases (total, durables, nondurables and services), fixed investments (residential, nonresidential, structures and inventories), monetary base, federal government expenditure and the consumer price index for the period $46,1-85,4(59,1-85,4$ for the monetary base). The sources of the data appear in Barsky and Miron (1989).

Table 2 reports the results of testing the following hypotheses:

- Does there exist seasonality in investments and inventory data? Is there still some form of seasonality after we extract deterministic seasonal components?

- Do GNP and CPI exhibit significant business cycle fluctuations? 
- Is there a "presidential election" cycle, i.e, is there a tendency for government expenditure and for the monetary base to follow a four year pattern?

- Are there significant cycles in consumption data?

To answer these questions I log first differenced all the data. Diagnostic testing on the residuals of an $\mathrm{AR}(5)$ regression on the log first difference of the data does not reveal any evidence of heteroschedasticity in any of the series examined.

With quarterly data, and given the symmetry of the spectrum around $\lambda=0$, seasonals appear at $\pi / 2$ and $\pi$ and business cycle frequencies are chosen to belong to the interval $[\pi / 12, \pi / 8]$.

Table 2 indicates that a yearly cycle $(r=4)$ is very significant for all investments and for the inventory series examined. All three tests detect the presence of cycles at seasonal frequencies although the significance of the first test is marginal for nonresidential fixed investments and inventories. Also, while for fixed residential and nonresidential investments seasonals are reasonably captured by deterministic dummies, investments in structures and inventories have significant seasonals even after a deterministic seasonal component is extracted. Note also that for the case of fixed nonresidential investment the distance-type test suggests the presence of seasonality after dummies are taken into account while the other two do not. This indicates that none of the peaks at seasonal frequencies is significant but that the total power appearing at seasonal frequencies is significant relative to the variance of the process.

The table also indicates that GNP possesses significant business cycle fluctuations (total power is significant at frequencies between $[\pi / 12, \pi / 8]$ and their harmonics), but it has neither a large mass nor a sharp peak anywhere in the region corresponding to cycles of $16-24$ quarters (the second and the third test statistics are insignificant). On the other hand, the CPI has no significant business cycle fluctuations, it has a large mass but no sharp peak in the region corresponding to 
cycles of $16-24$ quarters.

As far as political cycles are concerned, neither government expenditure nor the monetary base show any significant four years periodicity $(r=16)$. All three tests in fact do not reject the null hypotheses. Therefore, since in the second test the band covers frequencies corresponding to cycles between 14 and 18 quarters, it is unlikely that this type of periodicity is of crucial importance in accounting for fluctuations in the US economy.

Finally, when I search for the presence of cycles in the growth rate of consumption expenditure and of its three components I find very little evidence of deviations from the martingale hypothesis suggested by Hall (1978). For each series I search for the largest peak in the spectral density and test for its significance. Only the growth rate of consumption services displays very long cycles. The peak at $\frac{\pi}{24}$ is large and sharp enough to reject the null hypotheses in two of the three tests.

Next, I briefly address the question of the sensitivity of the results to alternative ways of eliminating the peak in the spectral density at frequency zero. Table 3 reports the results of testing the hypotheses of interest when the data is filtered with a linear trend, i.e. $X_{t}$ is the residual of $Y_{t}=a_{0}+a_{1} T_{t}+X_{t}$ or when it is filtered with the Hodrick and Prescott (1980) filter, i.e. where $X_{t}=Y_{t}-\tau_{t}$ and $\tau_{t}$ minimizes $\sum_{t=1}^{T}\left(Y_{t}-\tau_{t}\right)^{2}+\lambda \sum_{t=3}^{T}\left[\left(\tau_{t}-\tau_{t-1}\right)-\left(\tau_{t-1}-\tau_{t-2}\right)\right]^{2}$ where $\lambda$ is a smoothing parameter which, for quarterly data, is routinely set to 1600. Elsewhere (Canova (1991)), I have shown that the choice of detrending method is nonneutral with respect to the compilation of stylized business cycle facts where the cyclical component of the series is defined, following the current macroeconomic practice, as the deviation from the trend of the process. The question I am interested here is different. I would like to know if different detrending methods generate peaks of different size or location in the spectrum of the cyclical component of the series.

The table indicates that, as far as location is concerned, that results are not 
robust. For example, while there are significant periodic components in GNP with length of about 4 years when the data is first differenced, no significant 4-year periodicity exist in GNP when data is linearly detrended and some evidence in favour of 4 year cycles exist when data is filtered with the Hodrick and Prescott (HP) filter. Note, however, that when the HP filter is used, the three tests give results for $r=16$ which are the opposite of those obtained using log first differenced data. This result persists when we consider $r=24$ although in this case the third test provides different results. In those cases where there are no location distortions, e.g. inventory investments, the significance of the peaks is different depending on the first stage transformation used.

While these results do not come as a surprise since the gain functions of different filters "carve" out different amounts of variability in the original series, it is somewhat disturbing to see that location distortions are present. This confirms the results of Canova (1991) and raises doubts about the ability to compile a set of regularities for macro data which is independent of the stationary inducing transformation used.

\section{Conclusions}

This paper describes three tests to assess the significance of cycles in univariate time series. The tests are based on the frequency domain features of the series, do not require parametric assumptions and employ the properties of the integrated spectrum to derive the asymptotic distribution of the tests. The paper shows that the tests can be used to assess the significance of seasonal fluctuations, business cycle fluctuations or long but finite cycles and are powerful in detecting cycles of any length.

Although the tests are designed for univariate time series only, they can be extended to multivariate frameworks where propositions concerning the seasonal and cyclical behavior of a multitude of time series can be formulated and tested. 
These extensions will be presented in a subsequent paper. 


\section{Appendix}

Proof of Lemma 1: For linear processes satisfying assumptions 1 and $2, I_{n, x}\left(\lambda_{k}\right)=$ $0.5 h\left(\lambda_{k}\right) \frac{I_{n, e}\left(\lambda_{k}\right)}{\sigma_{e}^{2}}+R_{n}\left(\lambda_{k}\right)$ uniformly in $\lambda_{k}$, where for some $\gamma>0, E\left[R_{n}\left(\lambda_{k}\right)^{2}\right]=$ $O\left(\frac{1}{n^{2} \gamma}\right)$ (Priestley, 1981, p.424). Therefore, $2 \frac{I_{n, x}\left(\lambda_{k}\right)}{h\left(\lambda_{k}\right)}$ are, asymptotically, independently distributed random variables for each $\lambda_{k}$ and have the same distribution of $\frac{I_{n, e}\left(\lambda_{k}\right)}{\sigma_{e}^{2}}$. By normality of $e_{t}$

$$
\begin{aligned}
\frac{I_{n, x}\left(\lambda_{k}\right)}{h_{x}\left(\lambda_{k}\right)} & \sim \chi^{2}(1) \quad \text { if } k=0,\left[\frac{n}{2}\right] \\
& \sim 0.5 \chi^{2}(2) \quad \text { otherwise }
\end{aligned}
$$

For large enough $n, A_{1 n}$ and $A_{2 n}$ are linear combinations of independent variables each proportional to a $\chi^{2}$ distribution. Excluding $k=0$ and $k=\left[\frac{n}{2}\right]$, the weights in the summations are $\frac{2 \pi h_{x}\left(\lambda_{k}\right)}{M}$ and $\frac{2 \pi \cos \left(\lambda_{k} r\right) h_{x}\left(\lambda_{k}\right)}{M}$ respectively. Because the weights are unequal over the range of the summation, $A_{1 n}$ and $A_{2 n}$ are no longer $\chi^{2}$ distributed. Following Fuller $\left(1981\right.$, p.296) approximate the distribution of $A_{1 n}$ by $E\left(A_{1 n}\right) \chi^{2}\left(\nu_{1}\right) / \nu_{1}$ and that of $A_{2 n}$ by $E\left(A_{2 n}\right) \chi^{2}\left(\nu_{2}\right) / \nu_{2}$ where $\nu_{1}$ and $\nu_{2}$ are equivalent degrees of freedom given by $\frac{2 n}{\left.M \sum_{k} q(k / M)\right)^{2}}$ where $q\left(\frac{k}{M}\right)$ are the weights in each expression. Since as $n \rightarrow \infty$ both $\nu_{1}$ and $\nu_{2} \rightarrow \infty, J_{1 n}=\frac{1}{\sqrt{\nu_{1}}} \frac{A_{1 n}-E A_{1 n}}{\sqrt{\operatorname{var}\left(A_{1 n}\right)}}$ and $J_{2 n}=\frac{1}{\sqrt{\nu_{2}}} \frac{A_{2 n}-E A_{2 n}}{\sqrt{\operatorname{var}\left(A_{2 n}\right)}}$ have a asymptotic normal distribution with zero mean and unit variance where $E\left(A_{1 n}\right)=\frac{4 \pi}{n} \sum_{k} h_{n, x}\left(\lambda_{k}\right), E\left(A_{2 n}\right)=\frac{4 \pi}{n} \sum_{k} \cos \left(\lambda_{k} r\right) h_{n, x}\left(\lambda_{k}\right)$, $\operatorname{var}\left(A_{1 n}\right)=\frac{16 \pi^{2}}{n^{2}} \sum h_{n, x}^{2}\left(\lambda_{k}\right)$ and $\operatorname{var}\left(A_{2 n}\right)=\frac{16 \pi^{2}}{n^{2}} \sum \cos ^{2}\left(\lambda_{k} r\right) h_{n, x}^{2}\left(\lambda_{k}\right)$ (see e.g. Anderson, 1971, p.539, 545).

Proof of Corollary 1: The corollary follows from the fact that $J_{1 n}$ and $J_{2 n}$ are asymptotically $\mathcal{N}(0,1)$ variates.

Proof of Lemma 2: From (A.1), when $x_{t}$ is a white noise, $I_{n, x}\left(\lambda_{k}\right) \sim 0.5 \chi^{2}(2) \sigma_{x}^{2}$, for $k$ different from 0 and $\left[\frac{n}{2}\right]$. Therefore, for all such $\lambda_{k}, C_{1 n}$ and $C_{2 n}$ are weighted averages of $\chi^{2}$ with equal weights. Hence, $2 \| \Gamma|| C_{1 n} \sim 0.5 \chi^{2}(2 \| \Gamma||) \sigma_{x}^{2}$ and $2\|\Omega-\Gamma\| C_{2 n} \sim$ 
$0.5 \chi^{2}(2|| \Omega-\Gamma||) \sigma_{x}^{2}$ and $\lim _{n \rightarrow \infty} D_{n} \sim F(2|| \Gamma||, 2|| \Omega-\Gamma||)$ since $C_{1 n}$ and $C_{2 n}$ are asymptotically independent by construction. Since $\|\Omega\|$ can be chosen to grow with the sample size, $2\|\Omega-\Gamma\| \rightarrow \infty$ as $n \rightarrow \infty$ and $G_{n}=2\|\Omega-\Gamma\| D_{n} \stackrel{n \rightarrow \infty}{\rightarrow} \chi^{2}(2|| \Gamma||)$. Under the alternative $\frac{2 I_{n, x}\left(\lambda_{k}\right)}{h_{x}\left(\lambda_{k}\right)} \sim \chi^{2}(2)$ for each $\lambda_{k}$ in $\Gamma$ so that the distribution of $C_{1 n}$ is no longer a $\chi^{2}$. Using the procedure described in lemma $1 C_{1 n}$ can be approximated with a $\chi^{2}$ distribution. Therefore $G_{n}$ is approximately asymptotically distributed as $\frac{\chi^{2}\left(\nu_{1}\right) E(G)}{\nu_{3}}$ where $\nu_{3}=\frac{32 n\|\Gamma\|}{\sum_{k} h_{n, x}^{2}\left(\lambda_{k}\right)}$.

Proof of Lemma 3: Since (A.1) holds $E\left[I_{n, x}\left(\lambda_{k}\right)\right]=h_{x}\left(\lambda_{k}\right)+O\left(\frac{\log (n)}{n}\right)$ and $\operatorname{var}\left[I_{n, x}\left(\lambda_{k}\right)\right]=$ $h_{x^{2}}\left(\lambda_{k}\right)+O\left(\frac{1}{n}\right)$. Under $H_{0}, h_{x}\left(\lambda_{k}\right) \approx h_{\tilde{x}}\left(\lambda_{k}\right)$ at all $\lambda_{k}$ where $h_{\tilde{x}}$ is the spectral density of $\tilde{X}_{t}$. Therefore for $k \neq 0$ and $\left[\frac{n}{2}\right], \tilde{K}_{n} \sim 0.5 \chi^{2}\left(2\left(\left[\frac{n}{2}\right]-2\right)\right)$. As $n \rightarrow \infty$, $2\left(\left[\frac{n}{2}\right]-2\right) \rightarrow \infty$ so that asymptctically $2 \sqrt{\tilde{K}_{n}}$ has approximately the same distribution as $\mathcal{N}\left(\sqrt{4\left(\left[\frac{n}{2}\right]-1\right)-1}, 1\right)$ (see Hastings and Peakock, 1983, p.50). Under $H_{1}$

$$
\lim _{n \rightarrow \infty} 2 \sqrt{\tilde{K}_{n}}=\lim _{n \rightarrow \infty} 2 \sqrt{K_{n} \frac{h_{\tilde{x}}\left(\lambda_{k}\right)}{h_{x}\left(\lambda_{k}\right)}}=2 \sqrt{\sum_{k} W_{3}\left(\lambda_{k}\right) \chi^{2}(2)}
$$

where $W_{3}(\lambda)=1$ for $\lambda$ outside $\left(\lambda_{k} \pm \epsilon\right) . \quad \tilde{K}_{n}$ is a weighted average of $\chi^{2}$ 's with unit weight outside the band centered around $\lambda_{k}$ and weight given by $W_{3}\left(\lambda_{k}\right)$ inside the band. This weighted sum can be approximated by $E\left(\tilde{K}_{n}\right) \frac{\chi^{2}\left(\nu_{4}\right)}{\nu_{4}}$ where $\nu_{4}=\frac{2 n}{M \sum_{k} W_{3}\left(\lambda_{k}\right)^{2}}$ in the band around $\frac{2 \pi k}{r}$. Since $\nu_{4}>2\left(\left[\frac{n}{2}\right]-2\right)$, if cycles of mean length $\frac{r}{k}$ exist in the data, the value of $2 \sqrt{\tilde{K}_{n}}$ will exceed the $Z_{\alpha}$ value determined by the asymptotically normal approximation computed under $H_{0}$. 


\section{References}

[1] Alesina, A. and Roubini, N., 1990, "Political Business Cycles," Harvard University, manuscript.

[2] Anderson, T.W., 1971, Statistical Analysis of Time Series, (New York, N.Y., Wiley \& Sons).

[3] Barsky, R., Miron, J., 1989, "The Seasonal and the Business Cycle," Journal of Political Economy, 97, 503-534.

[4] Canova, F., 1989, "Seasonalities in Foreign Exchange Markets," Brown University, working paper 8902 .

[5] Canova, F., 1991, "Detrending and Business Cycle Facts," Brown University, working paper 9122 .

[6] Cochrane, J., 1988, "How Big is the Random Walk in Output ", Journal of Political Economy, 96, 893-920.

[7] Cogley, T. and J. Nason, 1991, "Effects of the Hodrick and Prescott filter on Integrated Time Series", manuscript, University of Washington.

[8] Durlauf, S., 1991, "Spectral Based Testing of the Martingale Hypothesis," Journal of Econometrics, 50(3), 355-376..

[9] Fama, E., 1984, "The Information in the Term Structure," Journal of Financial Economics, 13, 529-546.

[10] Fisher, R., 1929, "Tests of Significance in Harmonic Analysis", Proceedings of the Royal Society, Ser. A, 125, 54-59.

[11] Fuller, W., 1981, An Introduction to Statistical Time Series, (New York, N.Y., Wiley \& Sons).

[12] Ghysels, E., 1988, “ A Study toward a Dynamic Theory of Seasonality for Economic Time Series," Journal of the American Statistical Association, 450-453. 
[13] Gladysev, E.G., 1961, "Periodically Correlated Random Sequences," Soviet Mathematics, 2, 385-388.

[14] Granger, C., 1966, "The Typical Spectral Shape of an Economic Variable," Econometrica, 34, 150-161.

[15] Granger, C., 1979, "Seasonality: Causation, Interpretation and Implications," in A. Zellner, ed., Seasonal Analysis of Economic Time Series, Washington, D.C., US Department of Commerce.

[16] Granger, C. and Newbold, P., 1986, Forecasting Economic Time Series, New York, N.Y., Academic Press.

[17] Grenander, U. and Rosenblatt, 1957, Statistical Analysis of Stationary Time Series, (New York, N.Y., Wiley \& Sons).

[18] Hall, R., 1978, "Stochastic İmplications of the Life Cycle-Permanent Income Hypothesis: Theory and Evidence," Journal of Political Economy, 86, 971-987.

[19] Hansen, B., 1990, "Lagrange Multiplier Tests for Parameter Instability in Nonlinear Models", University of Rochester, manuscript.

[20] Hansen, L. and Sargent, T., 1990, “ Disguised Periodicity as Source of Seasonality,", University of Chicago, manuscript.

[21] Hastings, N.A.J. and J.B., Peacock 1983, Statistical Distributions, (New York, N.Y., Wiley \& Sons).

[22] Hodrick, R. and Prescott, E., 1980, "PostWar US Business Cycles: An Empirical Investigation", Discussion Paper 450, Carnegie Mellon University.

[23] Kydland, F. and Prescott, E., 1990, "Business Cycles: Real Facts and a Monetary Myth", Federal Reserve Bank of Minneapolis, Quarterly Review Spring, 3-18.

[24] Kirman, A., 1990, "Epidemics of Opinions and Speculative Bubbles in Financial Markets," European University Institute, manuscript. 
[25] Nelson, C. and Kang, M., 1981, "Spurious periodicity in Inappropriately Detrendend Time Series" Econometrica, 49, 741-751.

[26] Nelson, and Plosser, C., 1982, "Trends and Random Walks in Macroeconomic Time Series," Journal of Monetary Economics, 10, 139-167.

[27] Lo, A. and MacKinlay, C., 1988, " Stock Market prices do not follow a random walk: Evidence from a simple specification test ", Review of Financial Studies, $1,41-66$.

[28] Nyarko, Y., 1990, "Bayesian Rationality and Learning Without Common Priors," New York University, working paper 9045.

[29] Poterba, J. and Summers, L., 1988, “Mean Reversion in Stock Prices: Evidence and Implications," Massachussets Institute of Technology, working paper 457.

[30] Priestley, M.B., 1981, Spectral Analysis and Time Series, (New York, N.Y., Academic Press).

[31] Quah, D., 1992, "The Relative Importance of Permanent and Transitory Components: Identification and Some Theoretical Bounds", forthcoming, Econometrica.

[32] Quah, D. and Wooldridge, J., 1988,

[33] Sargent, T., 1986, Macroeconomic Theory, 2nd edition, New York, N.Y., Academic Press.

[34] Sims, C., 1974, "Seasonality in Regression", Journal of the American Statistical Association, 69, 618-626.

[35] Tiao, G. and Grupe, M., 1980, "Hidden Periodic Autoregressive-Moving Average Models in Time Series Data," Biometrika 67(2), 365-373.

[36] Walker, P., 1965, "Some Asymptotic Results for the Periodogram of Stationary Time Series," Journal of the Australian Mathematical Society 5, 107-128.

[37] Whittle, P., 1952, “Tests for Fit in Time Series," Biometrika, 39, 309. 
Table 1: Small Sample Properties of the Tests. Percentage of rejections of the null hypothesis over 1000 replications. Simulated data.

Data Generating Mechanism: $X_{t}=5.0+b X_{t-1}+e_{t}$

\begin{tabular}{lcccc}
\hline \hline Value of $\mathrm{b}$ & value of $\mathrm{r}$ & Test 1 & Test 2 & Test 3 \\
\hline \hline-0.90 & 2 & $92.8 / 94.5$ & $91.0 / 93.4$ & $89.9 / 84.7$ \\
& 4 & $87.3 / 90.4$ & $8.0 / 6.0$ & $11.7 / 7.2$ \\
\hline-0.20 & 2 & $7.9 / 5.9$ & $17.3 / 13.8$ & $12.3 / 9.9$ \\
& 4 & $8.6 / 6.2$ & $8.4 / 7.7$ & $5.1 / 5.1$ \\
\hline \hline
\end{tabular}

Data Generating Mechanism: $X_{t}=5.0+b X_{t-4}+e_{t}$

\begin{tabular}{lcccc}
\hline \hline Value of $\mathrm{b}$ & value of $\mathrm{r}$ & Test 1 & Test 2 & Test 3 \\
\hline \hline-0.85 & 8 & $94.5 / 95.1$ & $94.2 / 94.7$ & $92.8 / 93.9$ \\
& 4 & $85.3 / 86.5$ & $4.8 / 5.0$ & $5.1 / 5.9$ \\
\hline+0.85 & 4 & $95.1 / 94.7$ & $83.6 / 92.8$ & $59.1 / 66.6$ \\
& 24 & $65.3 / 81.2$ & $6.2 / 6.1$ & $7.6 / 6.9$ \\
\hline-0.30 & 8 & $6.6 / 5.2$ & $8.8 / 7.3$ & $14.2 / 11.7$ \\
& 4 & $5.1 / 5.1$ & $6.1 / 5.7$ & $7.3 / 7.2$ \\
\hline+0.30 & 4 & $6.8 / 5.6$ & $9.8 / 8.0$ & $7.9 / 6.6$ \\
& 24 & $5.3 / 5.1$ & $7.0 / 6.3$ & $10.8 / 9.7$ \\
\hline \hline
\end{tabular}

Data Generating Mechanism: $X_{t}=5.0+b X_{t-1}+c X_{t-7}+d X_{t-20}+e_{t}$

\begin{tabular}{ccccc}
\hline \hline Value of b, c, d & value of $\mathrm{r}$ & Test 1 & Test 2 & Test 3 \\
\hline \hline$-0.68,0.16,-0.34$ & 14 & $92.6 / 94.5$ & $88.6 / 91.7$ & $90.3 / 92.8$ \\
& 7 & $87.3 / 81.4$ & $6.3 / 5.8$ & $9.6 / 8.7$ \\
\hline $0.80,-0.22,0.30$ & 20 & $94.6 / 95.2$ & $90.4 / 92.0$ & $89.9 / 93.6$ \\
& 8 & $5.8 / 5.3$ & $6.6 / 6.1$ & $8.1 / 7.3$ \\
\hline \hline
\end{tabular}

Data Generating Mechanism: $X_{t}=e_{t}+f e_{t-1}$

\begin{tabular}{lcccc}
\hline \hline Value of $\mathbf{f}$ & value of $\mathbf{r}$ & Test 1 & Test 2 & Test 3 \\
\hline \hline 0.80 & 4 & $5.2 / 5.1$ & $6.3 / 5.7$ & $5.9 / 5.1$ \\
& 8 & $5.3 / 5.1$ & $6.1 / 5.5$ & $6.5 / 5.8$ \\
\hline 0.20 & 4 & $5.1 / 5.0$ & $6.1 / 5.4$ & $6.3 / 5.7$ \\
& 8 & $4.8 / 4.8$ & $5.8 / 5.2$ & $6.4 / 5.8$ \\
\hline \hline
\end{tabular}

Data Generating Mechanism: $X_{t}=e_{t}$

\begin{tabular}{cccc}
\hline \hline value of $\mathrm{r}$ & Test 1 & Test 2 & Test 3 \\
\hline \hline & $5.6 / 4.9$ & $7.2 / 6.1$ & $5.8 / 5.1$ \\
\hline \hline
\end{tabular}

Note: In each cell for the first number refers to $n=60$, the second $n=154$.

For all cases $e_{t}$ is i.i.d. $\mathcal{N}(0,1)$. 
Table 2: Tests for Cycles in US Data, Sample 1946,1-1985,4

Log First Differenced Data

\begin{tabular}{|c|c|c|c|}
\hline & $\begin{array}{c}\text { Test } 1 \\
\text { P-Value }\end{array}$ & $\begin{array}{c}\text { Test } 2 \\
\text { P-Value }\end{array}$ & $\begin{array}{c}\text { Test } 3 \\
\text { P-Value }\end{array}$ \\
\hline & \multicolumn{3}{|c|}{ Seasonality } \\
\hline Non Residential Fixed Investments & 0.06 & $0.00 / 0.00$ & $0.00 / 0.08$ \\
\hline (with dummies) & 0.00 & $0.06 / 0.06$ & $0.34 / 0.56$ \\
\hline Non Residential Structures & 0.00 & $0.00 / 0.00$ & $0.00 / 0.03$ \\
\hline (with dummies) & NA & $0.00 / 0.00$ & $0.19 / 0.18$ \\
\hline Residential Fixed Investments & 0.00 & $0.00 / 0.00$ & $0.00 / 0.05$ \\
\hline (with dummies) & NA & $0.12 / 0.99$ & $0.29 / 0.47$ \\
\hline Inventories & 0.06 & $0.00 / 0.01$ & $0.39 / 0.66$ \\
\hline \multirow[t]{2}{*}{ (with dummies) } & NA & $0.00 / 0.31$ & $0.59 / 0.81$ \\
\hline & \multicolumn{3}{|c|}{ Business Cycles } \\
\hline GNP $\quad r=16$ & 0.00 & 0.99 & 0.03 \\
\hline GNP $\quad r=24$ & 0.005 & 0.99 & 0.92 \\
\hline CPI $r=16$ & NA & 0.006 & 0.76 \\
\hline \multirow[t]{2}{*}{ CPI $\quad r=24$} & NA & 0.00 & 0.88 \\
\hline & \multicolumn{3}{|c|}{ Political Cycles } \\
\hline Government Expenditure $r=16$ & NA & 0.33 & 0.16 \\
\hline \multirow[t]{2}{*}{ Monetary Base $r=16$} & 0.90 & 0.14 & 0.12 \\
\hline & \multicolumn{3}{|c|}{ Deviations from a martingale behavior } \\
\hline Total Consumption & NA & 0.23 & 0.40 \\
\hline Durables & NA & 0.85 & 0.60 \\
\hline Non-Durables & NA & 0.29 & 0.40 \\
\hline Services & 0.03 & 0.00 & 0.08 \\
\hline
\end{tabular}

Note: In the case of seasonality the cell for the second and the third tests report the p-value at $\frac{\pi}{2}$ first and the p-value at $\pi$ second. NA indicates that $2 A_{2 n}<0$. 
Table 3: Tests for Cycles in US Data, Sample 1946,1-1985,4. Linearly Detrended Data

\begin{tabular}{|c|c|c|c|}
\hline & $\begin{array}{c}\text { Test } 1 \\
\text { P-Value }\end{array}$ & $\begin{array}{c}\text { Test } 2 \\
\text { P-Value }\end{array}$ & $\begin{array}{c}\text { Test } 3 \\
\text { P-Value }\end{array}$ \\
\hline & \multicolumn{3}{|c|}{ Seasonality } \\
\hline Non Residential Fixed Investments (with dummies) & 0.54 & $0.99 / 0.99$ & $0.23 / 0.34$ \\
\hline Non Residential Structures (with dummies) & 0.04 & $0.99 / 0.99$ & $0.07 / 0.08$ \\
\hline Residential Fixed Investments (with dummies) & 0.08 & $0.99 / 0.99$ & $0.65 / 0.30$ \\
\hline \multirow[t]{2}{*}{ Inventories (with dummies) } & NA & $0.52 / 0.04$ & $0.94 / 0.27$ \\
\hline & \multicolumn{3}{|c|}{ Business Cycles } \\
\hline GNP $\quad r=16$ & 0.70 & 0.74 & 0.40 \\
\hline GNP $\quad r=24$ & NA & 0.79 & 0.73 \\
\hline CPI $r=16$ & NA & 0.97 & 0.40 \\
\hline \multirow[t]{2}{*}{ CPI $\mathbf{r}=24$} & NA & 0.72 & 0.97 \\
\hline & \multicolumn{3}{|c|}{ Political Cycles } \\
\hline Government Expenditure $r=16$ & NA & 0.11 & 0.48 \\
\hline Monetary Base $\mathrm{r}=16$ & NA & 0.03 & 0.04 \\
\hline
\end{tabular}

Hodrick and Prescott Filtered Data

\begin{tabular}{|c|c|c|c|}
\hline & $\begin{array}{c}\text { Test } 1 \\
\text { P-Value }\end{array}$ & $\begin{array}{c}\text { Test } 2 \\
\text { P-Value }\end{array}$ & $\begin{array}{c}\text { Test } 3 \\
\text { P-Value }\end{array}$ \\
\hline & \multicolumn{3}{|c|}{ Seasonality } \\
\hline Non Residential Fixed Investments (with dummies) & $\mathrm{NA}$ & $0.00 / 0.98$ & $0.00 / 0.79$ \\
\hline Non Residential Structures (with dummies) & NA & $0.00 / 0.05$ & $0.00 / 0.08$ \\
\hline Residential Fixed Investments (with dummies) & NA & $0.98 / 0.00$ & $0.55 / 0.03$ \\
\hline \multirow[t]{2}{*}{ Inventories (with dummies) } & NA & $0.00 / 0.18$ & $0.73 / 0.31$ \\
\hline & \multicolumn{3}{|c|}{ Business Cycles } \\
\hline GNP $\quad r=16$ & NA & 0.00 & 0.45 \\
\hline GNP $\quad r=24$ & NA & 0.00 & 0.00 \\
\hline CPI $r=16$ & NA & 0.03 & 0.46 \\
\hline \multirow[t]{2}{*}{ CPI $\quad r=24$} & NA & 0.00 & 0.00 \\
\hline & \multicolumn{3}{|c|}{ Political Cycles } \\
\hline Government Expenditure $r=16$ & NA & 0.75 & 0.62 \\
\hline Monetary Base $r=16$ & NA & 0.32 & 0.78 \\
\hline
\end{tabular}




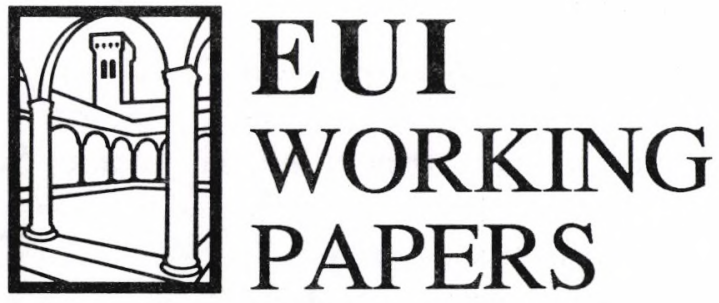

EUI Working Papers are published and distributed by the European University Institute, Florence

Copies can be obtained free of charge - depending on the availability of stocks - from:

The Publications Officer

European University Institute

Badia Fiesolana

I-50016 San Domenico di Fiesole (FI)

Italy

Please use order form overleaf 


\section{圖 \\ Publications of the European University Institute \\ Economics Department Working Paper Series}

To Economics Department WP

European University Institute

Badia Fiesolana

I-50016 San Domenico di Fiesole (FI)

Italy

From

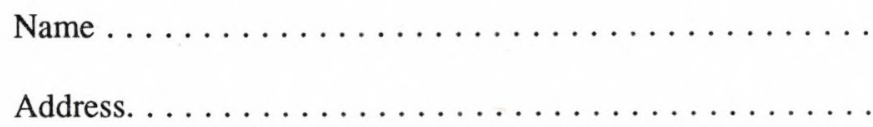

(Please print)

$\square$ Please enter/confirm my name on EUI Economics Dept. Mailing List

$\square$ Please send me a complete list of EUI Working Papers

$\square$ Please send me a complete list of EUI book publications

$\square$ Please send me the EUI brochure Academic Year 1992/93

Please send me the following EUI ECO Working Paper(s):

No, Author

Title:

No, Author

Title:

No, Author

Title:

No, Author

Title:

Date

Signature 


\section{Working Papers of the Department of Economics Published since 1990}

ECO No. 90/1

Tamer BASAR and Mark SALMON Credibility and the Value of Information Transmission in a Model of Monetary Policy and Inflation

ECO No. 90/2

Horst UNGERER

The EMS - The First Ten Years

Policies - Developments - Evolution

ECO No. $90 / 3$

Peter J. HAMMOND

Interpersonal Comparisons of Utility: Why and how they are and should be made

ECO No. 90/4

Peter J. HAMMOND

A Revelation Principle for (Boundedly)

Bayesian Rationalizable Strategies

ECO No. 90/5

Peter J. HAMMOND

Independence of Irrelevant Interpersonal Comparisons

ECO No. 90/6

Hal R. VARIAN

A Solution to the Problem of

Externalities and Public Goods when

Agents are Well-Informed

ECO No. 90/7

Hal R. VARIAN

Sequential Provision of Public Goods

ECO No. 90/8

T. BRIANZA, L. PHLIPS and J.F. RICHARD

Futures Markets, Speculation and Monopoly Pricing

ECO No. 90/9

Anthony B. ATKINSON/ John

MICKLEWRIGHT

Unemployment Compensation and

Labour Market Transition: A Critical

Review

ECO No. 90/10

Peter J. HAMMOND

The Role of Information in Economics
ECO No. 90/11

Nicos M. CHRISTODOULAKIS

Debt Dynamics in a Small Open

Economy

ECO No. 90/12

Stephen C. SMITH

On the Economic Rationale for

Codetermination Law

ECO No. 90/13

Elettra AGLIARDI

Learning by Doing and Market Structures

ECO No. 90/14

Peter J. HAMMOND

Intertemporal Objectives

ECO No. 90/15

Andrew EVANS/Stephen MARTIN

Socially Acceptable Distortion of

Competition: EC Policy on State Aid

ECO No. 90/16

Stephen MARTIN

Fringe Size and Cartel Stability

ECO No. 90/17

John MICKLEWRIGHT

Why Do Less Than a Quarter of the

Unemployed in Britain Receive

Unemployment Insurance?

ECO No. 90/18

Mrudula A. PATEL

Optimal Life Cycle Saving With

Borrowing Constraints:

A Graphical Solution

ECO No. 90/19

Peter J. HAMMOND

Money Metric Measures of Individual and Social Welfare Allowing for Environmental Externalities

ECO No. 90/20

Louis PHLIPS/

Ronald M. HARSTAD

Oligopolistic Manipulation of Spot

Markets and the Timing of Futures

Market Speculation 
ECO No. 90/21

Christian DUSTMANN

Earnings Adjustment of Temporary

Migrants

ECO No. 90/22

John MICKLEWRIGHT

The Reform of Unemployment

Compensation:

Choices for East and West

ECO No. 90/23

Joerg MAYER

U. S. Dollar and Deutschmark as

Reserve Assets

ECO No. 90/24

Sheila MARNIE

Labour Market Reform in the USSR:

Fact or Fiction?

ECO No. 90/25

Peter JENSEN/

Niels WESTERGÅRD-NIELSEN

Temporary Layoffs and the Duration of

Unemployment: An Empirical Analysis

ECO No. 90/26

Stephan L. KALB

Market-Led Approaches to European

Monetary Union in the Light of a Legal

Restrictions Theory of Money

ECO No. 90/27

Robert J. WALDMANN

Implausible Results or Implausible Data?

Anomalies in the Construction of Value

Added Data and Implications for Esti-

mates of Price-Cost Markups

ECO No. 90/28

Stephen MARTIN

Periodic Model Changes in Oligopoly

ECO No. 90/29

Nicos CHRISTODOULAKIS/

Martin WEALE

Imperfect Competition in an Open

Economy
* * *

ECO No. 91/30

Steve ALPERN/Dennis J. SNOWER

Unemployment Through 'Learning From

Experience'

ECO No. 91/31

David M. PRESCOTT/Thanasis

STENGOS

Testing for Forecastible Nonlinear

Dependence in Weekly Gold Rates of

Return

ECO No. 91/32

Peter J. HAMMOND

Harsanyi's Utilitarian Theorem:

A Simpler Proof and Some Ethical

Connotations

ECO No. 91/33

Anthony B. ATKINSON/

John MICKLEWRIGHT

Economic Transformation in Eastern

Europe and the Distribution of Income

ECO No. 91/34

Svend ALBAEK

On Nash and Stackelberg Equilibria

when Costs are Private Information

ECO No. 91/35

Stephen MARTIN

Private and Social Incentives

to Form R \& D Joint Ventures

ECO No. 91/36

Louis PHLIPS

Manipulation of Crude Oil Futures

ECO No. 91/37

Xavier CALSAMIGLIA/Alan KIRMAN

A Unique Informationally Efficient and

Decentralized Mechanism With Fair

Outcomes

ECO No. 91/38

George S. ALOGOSKOUFIS/

Thanasis STENGOS

Testing for Nonlinear Dynamics in

Historical Unemployment Series

ECO No. 91/39

Peter J. HAMMOND

The Moral Status of Profits and Other

Rewards:

A Perspective From Modern Welfare

Economics 
ECO No. 91/40

Vincent BROUSSEAU/Alan KIRMAN

The Dynamics of Learning in Mis-

Specified Models

ECO No. 91/41

Robert James WALDMANN

Assessing the Relative Sizes of Industryand Nation Specific Shocks to Output

ECO No. 91/42

Thorsten HENS/Alan KIRMAN/Louis PHLIPS

Exchange Rates and Oligopoly

ECO No. 91/43

Peter J. HAMMOND

Consequentialist Decision Theory and Utilitarian Ethics

ECO No. 91/44

Stephen MARTIN

Endogenous Firm Efficiency in a Cournot Principal-Agent Model

ECO No. 91/45

Svend ALBAEK

Upstream or Downstream Information Sharing?

ECO No. 91/46

Thomas H. McCURDY/

Thanasis STENGOS

A Comparison of Risk-Premium

Forecasts Implied by Parametric Versus

Nonparametric Conditional Mean

Estimators

ECO No. 91/47

Christian DUSTMANN

Temporary Migration and the Investment into Human Capital

ECO No. 91/48

Jean-Daniel GUIGOU

Should Bankruptcy Proceedings be

Initiated by a Mixed

Creditor/Shareholder?

ECO No. 91/49

Nick VRIEND

Market-Making and Decentralized Trade

ECO No. 91/50

Jeffrey L. COLES/Peter J. HAMMOND

Walrasian Equilibrium without Survival:

Existence, Efficiency, and Remedial

Policy
ECO No. 91/51

Frank CRITCHLEY/Paul MARRIOTT/ Mark SALMON

Preferred Point Geometry and Statistical Manifolds

ECO No. 91/52

Costanza TORRICELLI

The Influence of Futures on Spot Price

Volatility in a Model for a Storable

Commodity

ECO No. 91/53

Frank CRITCHLEY/Paul MARRIOTT/

Mark SALMON

Preferred Point Geometry and the Local Differential Geometry of the Kullback-

Leibler Divergence

ECO No. 91/54

Peter MØLLGAARD/

Louis PHLIPS

Oil Futures and Strategic

Stocks at Sea

ECO No. 91/55

Christian DUSTMANN/

John MICKLEWRIGHT

Benefits, Incentives and Uncertainty

ECO No. 91/56

John MICKLEWRIGHT/

Gianna GIANNELLI

Why do Women Married to Unemployed

Men have Low Participation Rates?

ECO No. 91/57

John MICKLEWRIGHT

Income Support for the Unemployed in Hungary

ECO No. 91/58

Fabio CANOVA

Detrending and Business Cycle Facts

ECO No. 91/59

Fabio CANOVAV

Jane MARRINAN

Reconciling the Term Structure of Interest Rates with the Consumption Based ICAP Model

ECO No. 91/60

John FINGLETON

Inventory Holdings by a Monopolist Middleman 
ECO No. 92/61

Sara CONNOLLY/John

MICKLEWRIGHT/Stephen NICKELL

The Occupational Success of Young Men

Who Left School at Sixteen

ECO No. 92/62

Pier Luigi SACCO

Noise Traders Permanence in Stock

Markets: A Tâtonnement Approach.

I: Informational Dynamics for the Two-

Dimensional Case

ECO No. 92/63

Robert J. WALDMANN

Asymmetric Oligopolies

ECO No. 92/64

Robert J. WALDMANN/Stephen

C. SMITH

A Partial Solution to the Financial Risk and Perverse Response Problems of Labour-Managed Firms: IndustryAverage Performance Bonds

ECO No. 92/65

Agustín MARAVALL/Víctor GÓMEZ

Signal Extraction in ARIMA Time Series Program SEATS

ECO No. 92/66

Luigi BRIGHI

A Note on the Demand Theory of the Weak Axioms

ECO No. 92/67

Nikolaos GEORGANTZIS

The Effect of Mergers on Potential

Competition under Economies or

Diseconomies of Joint Production

ECO No. 92/68

Robert J. WALDMANN/

J. Bradford DE LONG

Interpreting Procyclical Productivity:

Evidence from a Cross-Nation Cross-

Industry Panel

ECO No. 92/69

Christian DUSTMANN/John

MICKLEWRIGHT

Means-Tested Unemployment Benefit and Family Labour Supply: A Dynamic

Analysis
ECO No. 92/70

Fabio CANOVA/Bruce E. HANSEN

Are Seasonal Patterns Constant Over

Time? A Test for Seasonal Stability

ECO No. 92/71

Alessandra PELLONI

Long-Run Consequences of Finite

Exchange Rate Bubbles

ECO No. 92/72

Jane MARRINAN

The Effects of Government Spending on

Saving and Investment in an Open

Economy

ECO No. 92/73

Fabio CANOVA and Jane MARRINAN

Profits, Risk and Uncertainty in Foreign

Exchange Markets

ECO No. 92/74

Louis PHLIPS

Basing Point Pricing, Competition and

Market Integration

ECO No. 92/75

Stephen MARTIN

Economic Efficiency and Concentration: Are Mergers a Fitting Response?

ECO No. 92/76

Luisa ZANCHI

The Inter-Industry Wage Structure:

Empirical Evidence for Germany and a

Comparison With the U.S. and Sweden

ECO NO. 92/77

Agustín MARAVALL

Stochastic Linear Trends: Models and

Estimators

ECO No. $92 / 78$

Fabio CANOVA

Three Tests for the Existence of Cycles in Time Series 


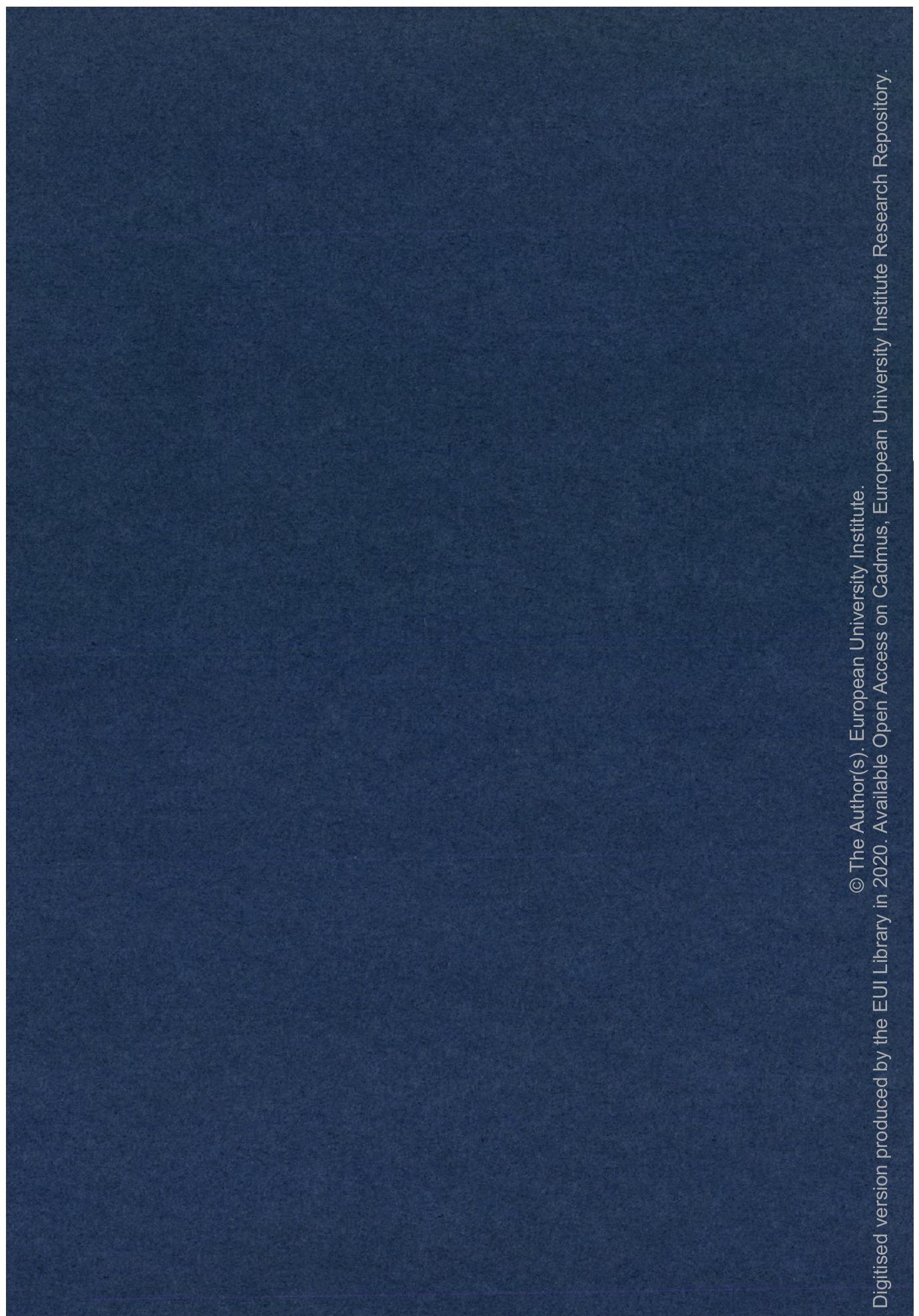


